
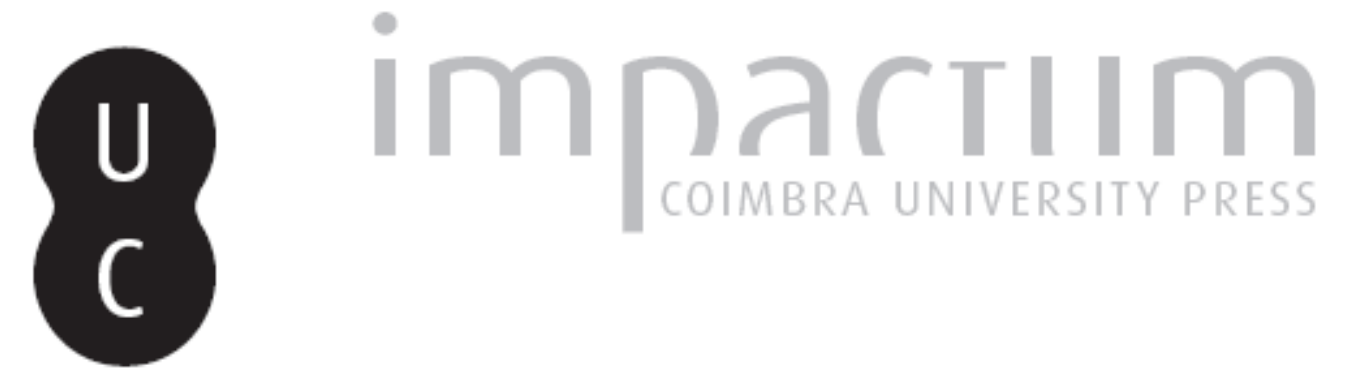

\title{
Fernando Pessoa e a consciência infeliz
}

\section{Autor(es): $\quad$ Ferrer, Diogo}

Publicado por: Faculdade de Letras da Universidade de Coimbra, Instituto de Estudos

\section{URL}

persistente:

URI:http://hdl.handle.net/10316.2/33458

DOI:

DOI:http://dx.doi.org/10.14195/0872-0851_33_10

Accessed : $\quad$ 26-Apr-2023 13:57:22

A navegação consulta e descarregamento dos títulos inseridos nas Bibliotecas Digitais UC Digitalis, UC Pombalina e UC Impactum, pressupõem a aceitação plena e sem reservas dos Termos e Condições de Uso destas Bibliotecas Digitais, disponíveis em https://digitalis.uc.pt/pt-pt/termos.

Conforme exposto nos referidos Termos e Condições de Uso, o descarregamento de títulos de acesso restrito requer uma licença válida de autorização devendo o utilizador aceder ao(s) documento(s) a partir de um endereço de IP da instituição detentora da supramencionada licença.

Ao utilizador é apenas permitido o descarregamento para uso pessoal, pelo que o emprego do(s) título(s) descarregado(s) para outro fim, designadamente comercial, carece de autorização do respetivo autor ou editor da obra.

Na medida em que todas as obras da UC Digitalis se encontram protegidas pelo Código do Direito de Autor e Direitos Conexos e demais legislação aplicável, toda a cópia, parcial ou total, deste documento, nos casos em que é legalmente admitida, deverá conter ou fazer-se acompanhar por este aviso.

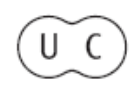




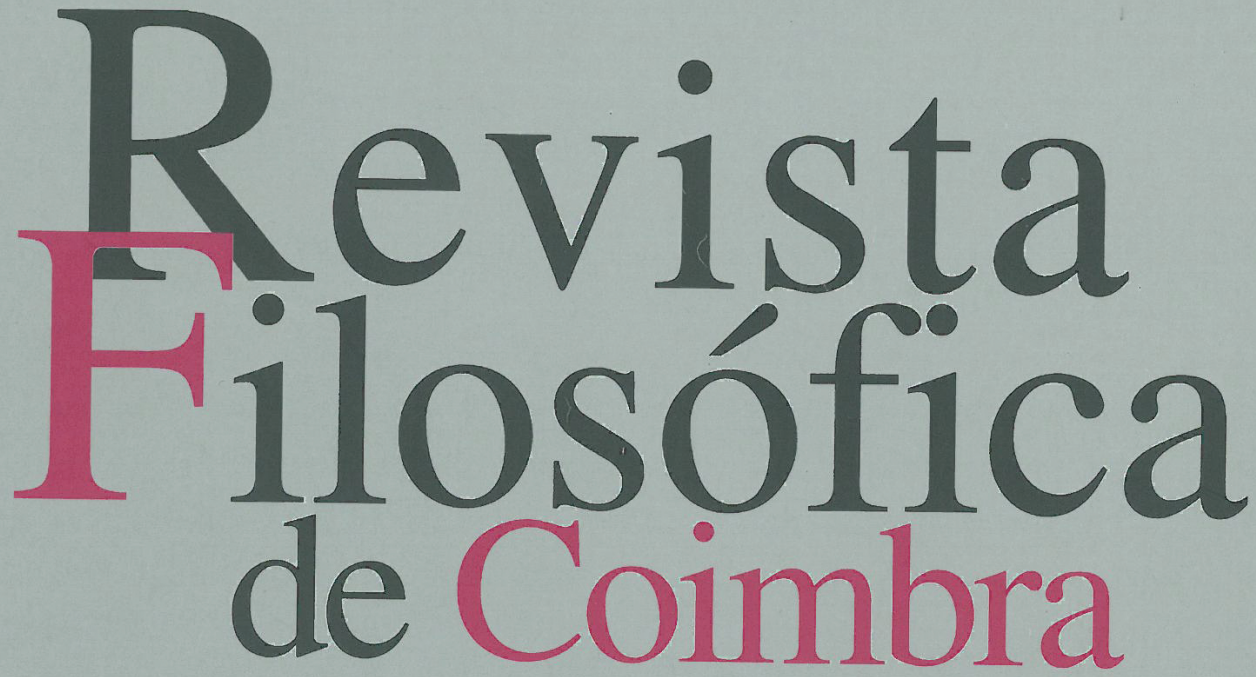

vol.17| n. .33 | 2008

Mário Santiago de Carvalho Fernanda Bernardo Luís António Umbelino Jean-Christophe Goddard Rui Alexandre Grácio Artur Ramos Luís M. Augusto Maria Luísa Portocarrero Jérôme Porée Diogo Ferrer Cláudio Alexandre Carvalho 


\section{FERNANDO PESSOA E A CONSCIÊNCIA INFELIZ}

DIOGO FERRER

(Universidade de Coimbra)

Resumo: Este artigo procura mostrar que a categoria da dupla negação, conhecida desde a Antiguidade, desempenha uma função maior na obra de Pessoa. Muitos dos temas do poeta, como o da identidade e da sua perda, a sensação pura, o "outrar-se" ou a dor, entre outros, podem ser estudados a partir de categorias relacionadas com a negatividade e a sua duplicação. São, como conclusão, esboçadas teses acerca de como, a vida e a obra de Pessoa, a duplicação da negação permitiu-lhe "passar além da dor" e restaurar modos de positividade.

Résumé: Cet article essaye de montrer que la catégorie de la double négation, catégorie qui est connue dès l'Antiquité, joue un rôle majeur dans l'oeuvre de Pessoa. Plusieurs thèmes du poète, comme l'identité et sa perte, la pure sensation, le "outrar-se" ["s'autrer", sc., "devenir un autre"] ou la douleur, par exemple, peuvent être étudiés à partir des catégories de la négativité et de sa duplication. Comme conclusion, l'article esquisse quelques thèses sur ce que la duplication de la négation a permis au poète, dans sa vie et son oeuvre: d' "aller au-delà de la douleur" et de restaurer des modes de la positivité.

Se for possível apreender o pensamento e a poesia de Fernando Pessoa com alguma unidade, no seu todo, isso só poderá ser feito em redor de um centro conceptual - e vital - onde está condensado um antigo problema dialéctico-argumentativo e conceptual, que procuraremos esclarecer no que se segue. Este núcleo poético corresponde a um antigo conceito dialéctico-argumentativo que permite definir, numa categoria, o problema poético e vital de Pessoa. Trata-se de um centro absolutamente diferencial, que permite diferenciar onde não há diferença, cuja essência, e cujo problema a pensar como insiste Hegel,

"é precisamente este, o de ser igual a si mesmo no ser-outro, ou na diferença. A diferença, por isso, é; mas perfeitamente transparente, e como uma diferença que, simultaneamente, não é nenhuma diferença." 

Pessoa sofre do mal, de origem conceptual, descrito por Hegel como o de

"diferenciar-se de si, de onde, simultaneamente, nenhuma diferença resulta."”

A virtualidade dialéctica e categorial deste centro é conhecida desde há muito, descoberto já na Antiguidade como a única categoria capaz de tornar discursivo algo de semelhante ao "cais absoluto" Pessoano, que os intérpretes procuraram na infância perdida, numa frustrada ânsia de totalidade ou como perdido numa culpabilidade infinita. ${ }^{3}$ A esta categoria o próprio ser tem ultimamente de se curvar " $v \alpha \alpha \varepsilon \lambda \tau_{\varepsilon} \omega \varsigma$ $\alpha v \varepsilon \imath v \alpha \imath$."4 Este "secretus, cuius non est simile," 5 atravessa a Idade Média e não se perde, mas agudiza-se na Modernidade, ${ }^{6}$ como a consciência do "espírito moderno, incapaz de fazer a síntese", em geral, do qual "nos ofereceu Fernando Pessoa uma das mais trágicas e geniais visões." 7

Esta diferença não é nenhuma diferença mas, estranhamente, não é tão-pouco alguma unidade resolutora da "consciência explodida" moderna. ${ }^{8}$ Ela permite ao ser ser completa e perfeitamente, na citada expressão

1 "Ihr Wesen ist eben dies, im Anderssein oder im Unterschiede unmittelbar sich selbst gleich zu sein. Der Unterschied ist daher; aber vollkommen durchsichtig, und als ein Unterschied, der zugleich keiner ist." (Hegel, Phänomenologie des Geistes, Hamburg, 1988, 160).

2 “...von sich zu untercheiden, worin zugleich kein Unterschied herauskömmt." (ib. 176).

3 Teses respectivamente de Gaspar Simões, Jacinto do Prado Coelho e Eduardo Lourenço, Pessoa Revisitado. Leitura Estruturante do Drama em Gente, Porto, 1973, 36 [= PR]), 115, 142; idem, Poesia e Metfísica. Camões, Antero e Pessoa, Lisboa, 1983 [=PM], 158.

4 “...para, por seu turno, ser perfeitamente.” (Platão, Parmenides, in Werke 5, Darmstadt, 1990, 162a).

5 "Segredo sem igual" (Nikolaus von Kues, Philosophisch-theologische Schriften, Band II, Wien, 1966, VI, 556).

${ }^{6}$ Para uma perspectiva histórica do tema v. Wolfgang Hübener, "Die Logik der Negation als ontologisches Erkenntnismittel" (in H. Weinrich (ed.), Positionen der Negativität, München, 1975, 105-140); e com um trabalho que abarca a literatura significativa desde Aristóteles até ao séc. XX, muito especialmente Klaus Hedwig, "Negatio Negationis. Problemgeschichtlkiche Aspekte einer Denkstruktur" (in Archiv für Begriffsgeschichte, 24 (1980), 7-33).

${ }^{7}$ Eduardo Lourenço, PM, Lisboa, 1983, 157.

${ }^{8}$ Lourenço, loc. cit. Ou então: "a única epopeia que a poesia moderna pode conceber [é] uma epopeia do negativo, da negação" (idem, $P R, 170$ ). Sobre a questão constitutiva da crise da consciência moderna, v. Vila Maior, O Sujeito Moderno - Fernando Pessoa, Mário de Sá Carneiro, Almada Negreiros e António Ferro. Crise e Superação do Sujeito, Lisboa, 2003, 51ss., 94ss. 
platónica, virtualidade de que Alberto Caeiro fez o adequado uso poético, mas a sua estranheza não se resolve de modo simples neste perfeito caeiriano deixar ser simplesmente. Mas é também a mesma estranheza do leitor que interroga perplexo como pode continuar a haver heterónimos depois de Caeiro, como há questão ainda depois da solução. ${ }^{9} \mathrm{O}$ ver simplesmente, e fazer/deixar perfeitamente ser com a visão "clara e directa" do mestre Caeiro, não pode fazer retornar a visão até uma posição inicial, porque o tema de que falamos não se extingue em nenhuma positividade resolutiva. Ele é, na verdade o que traz à linguagem a questão a que todo o ser é dado somente como resposta de tal modo que a continuidade do ser requer a continuidade da pergunta. Assim, a questão não acaba, nem a identidade se reúne num centro enfim encontrado, mas Caeiro, o ontologista a contrastar com a metafísica dos restantes heterónimos, ${ }^{10}$ morre, é legítimo supor-se $\imath v \alpha \quad \tau \varepsilon \lambda \varepsilon \omega \varsigma$ $\alpha v \varepsilon \imath v \alpha \imath \quad{ }^{11}$

$\mathrm{O}$ antigo conceito assim germinal que determina o pensamento de Pessoa é, entendemos, a par dos de não-ser, nada ou negatividade, o da negação, um dos que que com maior frequência irradia na obra pessoana em diferentes direcções temáticas e teóricas. ${ }^{12}$ A questão não escapou, é claro, à atenção dos estudos pessoanos, desde cedo identificada como elemento importante, ou mesmo central, para a interpretação da obra e, deverá acrescentar-se, também da vida do poeta, na medida em que esta possa interessar para a compreensão da obra daquele que chega a ser chamado o "poeta do Nada". ${ }^{13}$ A negação pode encontrar-se na forma poética e nos temas poéticos centrais da morte ou do tempo em Ricardo Reis, ${ }^{14}$ passando pela perda de sentido da realidade, com Bernardo Soares, a lucidez ultra-consciente de Pessoa ortónimo, a construção metafísica em diferentes versões, passando por um "Tratado da Negação" atribuído a um Rafael Baldaya, ${ }^{15}$ pela doença como condição de lucidez e realização

${ }^{9}$ A pergunta é de José Gil, que prossegue, "como se da solução nscessem os problemas" (José Gil, Diferença e Negação na Poesia de Fernando Pessoa, Lisboa, 1999 $[=\mathrm{DN}], 43)$.

10 A tese é de José Gil, $D N, 83,114,133-134$.

11 Ver nota 4 supra.

12 Observa correctamente Jorge de Sena a "tão espantosa e tão exemplar ciência de não-ser" de que dispôs Pessoa. (Jorge de Sena, Fernando Pessoa \& Conmpanhia Heterónima (Estudos Críticos 1940-1978), Lisboa, 1984 [=FP], 181).

13 Cf. Eduardo Lourenço, $P M, 166)$; idem, $P R, 36$. Ou "poeta da negação" segundo Sena $(F P, 193)$. Em especial num seminário onde o tema é a saúde, a ligação da poesia à vida não pode ser entendida como não interessante.

14 A ligação, pouco óbvia, é aludida por Lourenço, $P R, 64$.

15 Fernando Pessoa, Textos Filosóficos, Lisboa, 1968, II. 
estética em Álvaro de Campos ou igualmente no ortónimo, até uma certa forma de renúncia na sua vida pessoal e em fragmentos de tipo confessional.

Todos estes fenómenos não são desconexos, mas obedecem a uma lógica da negação de certo modo unitária, dotada de desdobramentos que produzem diferentes efeitos significativos, estéticos, teóricos e antropológicos. Trata-se, na verdade, de versões da negação em diferentes modalidades significativas, que contribuem decisivamente para a definição das figuras da consciência pessoana.

\section{A Negação na Consciência}

A negação pode ser encarada, num primeiro aspecto, como a operação que permite o retorno do mundo em direcção ao si-mesmo do poeta, teoreticamente por via de um cepticismo absoluto que acompanha a constatação da crise civilizacional, ${ }^{16}$ nacional, e também pessoal. A recondução do poeta a si-mesmo obedece à negação do mundo, que Pessoa intitula "irónica". ${ }^{17}$ À negação corresponde uma desrealização, que pode chegar a um grau extremo, do mundo, mas também, de modo que ainda se verá, e que não é de todo contraditória com esta desrealização, a afirmação da "espantosa objectividade do mundo [...]". ${ }^{18}$ Por que motivo não se excluem a desrealização integral, própria da identidade do eu, e a espantosa objectividade da realidade? Não se poderá dizer simplesmente, de modo injusto, que a imediatez de Caeiro não é senão resultado artificioso de um processo anterior de criação, como heterónimo de um outro Pessoa que por detrás da máscara Caeiro se esconde. ${ }^{19}$ Se a descrição tem um fundo de verdade, este fundo só pode ser correctamente definido se se observar que o mecanismo da criação de Caeiro, aquilo que este artificiosamente pressupõe é coisa nenhuma, nada. Ou, dito de outro modo, a imediatez de Caeiro não é propriamente resultado, mas tudo o que diz, diz a partir do ponto de vista da consciência da insignificância da consciência do ortónimo ou dos outros heterónimos que, como Reis, dizem, "nada nos falta, porque nada somos" 20 - uma vez que, natural-

\footnotetext{
${ }^{16}$ Cf. Vila Maior, op. cit., 65, 258-259, 296.

17 “A ironia é o primeiro indício de que a consciência se tornou consciente. [...] $\mathrm{O}$ primeiro passo chega àquele ponto em que duvidamos de nós dogmaticamente, e todo o homem superior o dá e atinge. O segundo passo chega àquele ponto em que duvidamos de nós e da nossa dúvida, e poucos homens o têm atingido [...]." (LD 165).

18 Bernardo Soares, Livro do Desassossego, ed. R. Zenith, Lisboa, 1998 [=LD], 392.

19 V. em E. Lourenço, $P R, 22-24$.

${ }^{20}$ Ricardo Reis, Poesia, ed. M. Parreira da Silva, Lisboa, 2000, 35.
} 
mente, se estes nada são, resta, livre de toda a posição de algum outro, a imediatez do primeiro olhar caeiriano sobre o mundo. Este nada que falta, ou que, da perspectiva negativa, justamente não falta por ser nada, e que, da perspectiva positiva, é descanso impossível do ser, é a visão plenamente objectiva. Tal visão só se torna possível, na sua imediatez, na medida em que o mecanismo que a produz é nada. O mecanismo subjacente não contamina, pois, de mediação, o sentido conceptual, filosófico e literário do Guardador de Rebanhos, e permite reconhecer originariamente a pureza da imediatez que reivindica. Muito pelo contrário, ela deverá explicar porque o problema que produz a heteronomia não cessa por Pessoa ter encontrado uma resposta poética e conceptual para o seu "drama em gente", mas prossegue sempre mais além.

Assim, a fenomenologia pessoana da consciência vai integrar o eu e o mundo num espaço intermédio produzido pela negatividade. A "objectividade" perfeita proclamada corresponde ainda claramente à atitude de recusa, não do mundo, mas da categoria da sua positividade, posto que, uma vez desrealizado em experiências da consciência que encontramos, por exemplo, frequentemente em Bernardo Soares, o mundo é também inteiramente aceite como a ultra-sensação de Campos. Contudo, a recusa do mundo que assim se complexifica, confronta-se igualmente com a humanidade, e afirma-se no repúdio de todo o sentimento para com a humanidade, e na perfeita indiferença relativamente à amizade, ao amor e ao outro em geral, numa recusa que ameaça assumir um carácter doentio por vezes mesmo irremediável.

Mas a negação é ainda, num segundo aspecto, a alteridade, o "outrarse", cujo lema é "viver é ser outro", ${ }^{21}$ o que o poeta entende como condição de estabelecimento da identidade. À identidade, na condição negativa da poesia de Pessoa, só se acede no espaço entre a sensação e o pensamento, ou no vazio da própria consciência. O outrar-se, no regime lógico subjectivo do autor, corresponde à multiplicação das personalidades e diferentes heterónimos. Não se pretende, é claro, deduzir ou reduzir o fenómeno da heteronimia à mera duplicação de um eu originalmente uno, por via da negação de si, mas somente mostrar, neste ponto, que a lógica da negação tem uma função, muito geral, de possibilitar a construção de múltiplas personalidades. A alteridade do eu em relação ao mundo e em relação a si mesmo deriva da construção negativa da consciência, em si mesma especular. $\mathrm{O}$ eu reflecte-se porque pode reflectir o mundo, e reflecte o mundo porque é capaz de estabelecer com ele uma relação mais complexa do que a da alteridade, ou do ser-outro. A indiferença perante

${ }^{21}$ LD 124. 
o mundo não significa só que é possível estar lado a lado com ele, que o mundo e o eu são dois, cujos modos específicos de relação não se confundem com os de duas coisas reais. Esta indiferença impõe, pelo contrário, uma categoria, de tipo dialéctico, que exige uma maior complexidade na tematização das relações da consciência consigo mesma e com o seu outro.

É Fernando Pessoa, agora pela pena de Bernardo Soares, que expõe o sentido duplo desta relação, partindo da exclusão negativa, passando pela experiência da dor, e chegando à sensibilidade, ou à sensação, nos seguintes termos.

"A exclusão, que me impus, dos fins e os movimentos da vida; a ruptura, que procurei, do meu contacto com as coisas - levou-me precisamente àquilo a que eu procurava fugir. Eu não queria sentir a vida, nem tocar nas coisas, sabendo, pela experiência do meu temperamento em contágio do mundo, que a sensação da vida era sempre dolorosa para mim. Mas ao evitar esse contacto, isolei-me, e, isolando-me, exacerbei a minha sensibilidade já excessiva. [...] Errei o método de fuga."22

Ou antes, esta fuga da simples exclusão não é um caminho praticável. $\mathrm{O}$ isolamento e protecção que a negação do mundo e da acção promove é uma arma de dois gumes, que fere a consciência ao confrontá-la, no isolamento, com a própria nulidade, que relança o mesmo eu para a relação com o mundo, agora desrealizado. O sentimento de angústia, teorizado nessa mesma época por Heidegger ou Sartre, ou mesmo de terror, em Pessoa, é inevitável. Desta perspectiva, a interioridade assente numa simples negação do exterior e do comércio com ele reconduz de facto a uma relação excessivamente estreita com esse mesmo mundo que se pretende rejeitar.

Mas, em que se funda esta ligação insuperável do eu ao mundo por via da sensibilidade exacerbada? Justamente, no facto já apontado de que o isolamento, por negação do mundo, não pode obedecer a um regime de negação imediata, mas tem de remeter sempre para as condições do espelhamento do eu por si mesmo. O eu não é um simples outro relativamente ao mundo, caso em que poderia eventualmente, dele se isolar e encerrar-se, mas é um outro reflexivo do mundo, o que significa que tem o mundo em si ao modo de uma realidade anulada. Este modo de ter o mundo é denominado sonho ou, mais propriamente, a sensibilidade que obsidiou Pessoa e que constitui nele um mundo próprio, com a sua geografia

\footnotetext{
22 LD 406-407.
} 
acidentada, ${ }^{23}$ os seus caminhos e organizações peculiares e as suas suas leis ontológicas, cognoscitivas e de acção próprias. Com Bernardo Soares, Pessoa propõe uma ciência de análise do sonho e da sensação dotados de um objectividade própria, independente do eu em sentido estrito. ${ }^{24}$

Esta constituição de um mundo que, numa primeira aproximação, diríamos tratar-se de um mundo de substituição, um duplo mental do mundo físico, não mantém, na verdade, com o mundo uma relação de duplicidade, mas pelo contrário, de identificação complexa. Aqui se abre o espaço das sensações, que pertencem ao eu, embora mantenham a sua autonomia própria de mundo, não se submetendo de modo nenhum à arbitrariedade do sujeito mas exige no melhor dos casos, um trabalho prévio de assimilação e de posse, cuja analogia nos é familiar no trabalho de formação, assimilação e maturação que torna possível uma acção eficaz sobre o mundo físico. Este trabalho ${ }^{25}$ descrito por Bernardo Soares, de mediação e assimilação, de formação e auto-formação antes de poder aceder ao trabalho sobre as sensações, esta necessidade de exercício para a elas aceder, na sua autonomia, manifestam bem o carácter de mundo que as sensações recebem para o poeta.

A forma estrutural do eu pessoano, que lhe permite ser imagem no sentido amplo de sensibilidade, é a da auto-referência. Compreender esta forma exige que se compreendam as condições de constituição de uma dualidade, tema que Pessoa tematiza em versões poéticas, mas também filosóficas, ou até esotéricas, cuja análise pode ser aprofundada fenomenológica e dialecticamente. A principal destas condições de constituição de uma dualidade, ou de uma qualquer série, não é difícil de enunciar: é requerido um plano comum sobre o qual os dois, ou os elementos da série, se colocam em relação. Este plano comum, no caso da sequência temporal organizada das sensações, é o da reflexão, que realiza um salto de nível hierárquico, permitindo, por assim dizer, "olhar para baixo" ou "para cima":

"Separo-me de mim e vejo que sou um fundo dum poço."26

Esta diferenciação de planos permite distinguir-se a si daquilo que está a ser visto, e exige, em consequência, para que se possa constituir a unidade onde os elementos comparados estão simultaneamente presentes, que o eu se veja a si mesmo.

23 "A geografia da consciência da realidade é de uma grande complexidade de costas, acidentadíssima de montanhas e e lagos." (LD 313).

${ }^{24}$ LD 433-436, 487.

25 LD 106-107.

${ }^{26}$ LD 361. 
Se esta descrição intencional é correcta, será necessário encontrar algum significado, poético e teórico, identicamente determinado, que produz simultaneamente o eu no isolamento perante o mundo e a relação de ser-outro, e, no novo movimento efectuado, permite compreender a desrealização e idealização que o mundo sofre no eu, e que o transforma em sensação, lá onde

“não há/Cá-dentro nem lá-fora". ${ }^{27}$

O conceito da duplicação que aqui se impõe é bastante claro na autoreflexão do poeta. Expressões reduplicadas, pouco inteligíveis sem a componente teórica que buscamos, são recorrentes: por exemplo "alma da alma" 28 ou "nada dentro de nada". ${ }^{29} \mathrm{O}$ eu remete sempre novamente para si mesmo. Mas aquilo que terá de ser aqui reencontrado para fundamentar esta descrição do surgimento do mundo da sensação a partir do repúdio do mundo físico, é afinal a reiteração da negação crítica e céptica. E este ponto, aparentemente especulativo e arbitrário, é repetidamente sentido e exposto por Pessoa. A negatividade já estudada está insistentemente presente no eu, sob diversas formas: "sou nada...", "vazio", "Ser eu é não ser", ${ }^{30}$ etc..., mas também sob um regime de reduplicação, em diversas versões:

"e tudo isto é uma visão que se extingue no mesmo momento em que é tida, um intervalo entre nada e nada [...]," ${ }^{11}$ ou

"Entre mim e o que em mim

É o quem eu me suponho,

Corre um rio sem fim." 32

A consciência, por conseguinte, é luminosamente entendida e sentida como vazio, não-ser e nada que permite constituir a identidade no mesmo passo em que a ameaça destruir, aliás, é essencialmente tempo, como especialmente Ricardo Reis tematiza. Esta figura conceptual é nítida em toda a obra do poeta, um tema permanente de uma poesia das sensações

${ }^{27}$ Fernando Pessoa, Obras Completas de Fernando Pessoa, Ática, Lisboa [=OC], 198712 , I, 64.
$28 O C, \mathrm{I}, 137$.
${ }^{29} \mathrm{RR}, 37$.
30 OC, VII, 45.
${ }^{31}$ LD 226.
$32 O C, \mathrm{I}, 175$. 
e da reflexão, e, na sua tradução para a vida, impõe-se como sofrimento inerente a toda a actividade consciente e, então, não pode deixar de se manifestar na conhecida dialéctica da consciência de Pessoa, de aparência paradoxal. Escreve Soares,

"a felicidade está fora da felicidade. Não há felicidade senão com conhecimento. Mas o conhecimento da verdade é infeliz [...]. Saber é matar, na felicidade como em tudo. Não saber, porém, é não existir."33

E Pessoa conhece o carácter hegeliano deste problema:

"só o absoluto de Hegel conseguiu, em páginas, ser duas coisas ao mesmo tempo. O não-ser e o ser não se fundem e confundem nas sensações e razões da vida: excluem-se, por uma síntese às avessas." ${ }^{34}$

Sumariando o que ficou dito, em Pessoa é a negatividade reiterada da consciência que produz o mundo como aparência desrealizada, em diferentes figuras, associadas a diferentes heterónimos ou ao ortónimo. A negatividade produz a interioridade e, reiterada, o reconhecimento de que o próprio eu é ilusão ou ainda, negativamente, a desrealização do mundo em que emergem as qualidades objectivas do mundo como espaço da sensação pura.

\section{A Vivência da dor e a patologia teórica associada}

A consciência pessoana reside, por conseguinte, sobre este fio da navalha de dois gumes que só pode constituir a sua consciência própria na negação do outro e na auto-consciência de si como negatividade pura, diríamos, em termos da teoria da dupla negação, uma negação da negação que reenvia ao seu outro e reencontra-o sob uma forma desrealizada nas sensações como um todo intencional desdobrável em correlatos do mundo e da consciência.

A expressão antropológica e vivencial desta sensação de si como nada, e do mundo como negado, é a dor, que se poderia alargar para um diagnóstico de crise civilizacional, europeia, ou mesmo da modernidade em geral, se não nos tivéssemos de cingir agora ao aspecto pessoal da doença. O poeta entende esta vivência da dor, na poesia e na autointerpretação íntima, como uma fonte não só de significação do mundo,

${ }^{33}$ LD 364.

$34 \mathrm{Ib}$. 
ou da falta dele, mas também como cânone estético, em formulações como se segue:

"Já que não podemos extrair beleza da vida, busquemos ao menos extrair beleza de não poder extrair beleza da vida." ${ }^{35}$

Na beleza plástica da poesia de Ricardo Reis encontramos esta beleza formal associada à consciência da alteração como passagem e sentimento de perda, mas o mesmo encontramos no ortónimo, onde surge em primeiro plano não tanto a plasticidade da linguagem, mas a riqueza da autoreflexão.

No entanto, a dor não é somente, ou essencialmente, a dor provocada pela consciência da nulidade própria, da desrealização e vazio do mundo e consequente desespero existencial, entendido como única atitude consentânea com a lucidez daquele que se conhece a si mesmo, ainda que sob a forma do saber da impossibilidade de se conhecer a si mesmo. A expressão deste pathos estético e teórico, conduz ao resultado de uma indefinição presa de paradoxos sobre o que seja o eu, a sua relação com o mundo e a sua possível felicidade. ${ }^{36}$

Mas poderíamos refazer agora o caminho de Pessoa como uma reflexão poética sobre a passagem do positivo ao negativo e as consequências dolorosas, antropológicas e existenciais, dessa passagem. Assim, a dor parece, de facto, provocada pela perda, como poderíamos exemplificar em textos como se segue.

"A noite, vindo como nada,

Lembra-me quem deixei de ser,

A curva anónima da estrada

Faz-me lembrar, faz-me esquecer,

Faz-me ter pena e ter de a ter." ${ }^{37}$

35 LD 290.

${ }^{36}$ Assim, por exemplo, em diversos temas e modalidades: "Pertenci sempre ao que não está onde estou e ao que nunca pude ser. [...] Nunca amei senão coisa nenhuma." (LD 121) $\mathrm{Ou}$ "os vencedores [...] ficam satisfeitos, e satisfeito só pode estar aquele que se conforma [...]. Vence só quem nunca consegue. Só é forte quem desanima sempre." (LD 132). "Nem a nossa alma é nossa sequer. Como, de resto, possuir uma alma? Entre alma e alma há o abismo de ter alma" (LD 329). "Para realizar um sonho é preciso esquecê-lo, distrair dele a atenção. Por isso realizar é não realizar." (LD 302) Etc...

37 OC, I, 127 (1930). 
Esta é a dor da saudade, que pode ser lida ao nível do simples sentimento daquilo que se perde no perpétuo fluxo do tornar-se outro, disso que sabemos e aprendemos sempre de novo, como da primeira vez, que não volta jamais. Este mal é irremediável, mas não é ainda o mal ontológico de existir que o poeta exprime. Seria, por isso, um erro procurarmos a origem fundamental desta dor na saudade. O mal é, na verdade, mais profundo, como enuncia Pessoa, distinguindo pena e sofrimento. A pena é pela perda do positivo, o sofrimento é a experiência consciente da negatividade mais geral, onde o positivo já não tem lugar. Lemos então:

"Ditosos a quem acena

Um lenço de despedida!

São felizes: têm pena...

Eu sofro sem pena a vida." 38

No plano dos sentimentos, ainda atravessados pela positividade do mundo e da vida, é a perda do objecto, ou da infância, ou das possibilidades, ou do que nunca se teve, que causa a dor. Mas a descoberta do poeta é que a verdadeira causa da dor não é, fundamentalmente, o positivo, i.e., as coisas, os momentos felizes ou os amores que se perdem, ou não tiveram, mas a negatividade do sujeito. O sofrimento é o de um afastamento e perda entendidos como existenciais, e revela-se num sentir excessivo, de tal modo que a saudade é feliz, por ter um ponto de apoio positivo, em comparação com a origem mais essencial da dor de uma identidade que não se pode cumprir num modo positivo, como realização, como acção, como conhecimento, como reconhecimento ou amor.

O problema, na verdade, contrariamente ao regime positivo, diríamos, ôntico da pena envolvida na saudade, não é o da perda, do objecto do amor ou da identidade própria, mas o do excesso da identidade, e do excesso da posse de si mesmo. A verdadeira saudade resulta não da pena pelo que passa, mas do sofrimento pela excessiva persistência do eu na sua identidade negativa. Isto é o que corta e ofende efectivamente o eu em dois. O poeta explica este contraste entre saudade e sofrimento como se segue.

"Vaga, no azul amplo solta,

Vai uma nuvem errando.

O meu passado não volta.

Não é o que estou chorando.

${ }^{38} O C$, I, 221 (1927). 
"O que choro é diferente.

Entra mais na alma da alma.

[...]

Não sei o que é nem consinto

À alma que o saiba bem.

Visto da dor com que minto

Dor que a minha alma tem."39

O problema, novamente, a fonte da dor é a excessiva permanência do eu em si mesmo, porque nesse estado a sua negatividade interna, que constitui a sua identidade, ameaça destruí-lo. A identidade do eu não é a identidade das coisas situadas ao nível do puro ser, onde umas são as outras das outras, mas a identidade de um ente especular, na superfície do qual se podem formar imagens. Ele não está, nestas condições, nem destinado à simples perda permanente de si, como as coisas, segundo Pessoa, o gato ou, até, na dramatização poética, a ceifeira, nem num regime de saber integral de si. Ou antes, o saber integral de si tem por único conteúdo material o negativo. ${ }^{40} \mathrm{~A}$ perda do sentido do ser é dita por Soares como uma cela:

"passar dos fantasmas da fé para os espectros da razão é somente ser mudado de cela." 41

A cela é da prisão no sujeito, cujos muros, conforme Pessoa os enuncia, constituem-se pela negatividade.

Esta prisão encontra-se já num texto juvenil, em termos que permitirão fazer avançar as nossas considerações. Diz Pessoa, provavelmente em 1910:

“... o sofrimento é um momento muito longo. Não o podemos dividir por estações. Apenas podemos notar os seus modos e registar a sua volta. Para nós o próprio tempo não avança. Revolve. Parece circular em torno de um só centro de dor. A imobilidade paralisante de uma vida da qual cada circunstância está regulada segundo um molde imutável, de modo que comemos e bebemos segundo as leis inflexíveis de uma fórmula de ferro: este carácter de imobilidade que faz cada horroroso dia no seu mínimo detalhe como todo outro dia parece transmitir-se àquelas forças exteriores[, e o texto

39 OC, I, 137 (1931).

40 Por exemplo: "Basta-nos, se pensarmos, a incompreensibilidade do universo; [...] porque ser homem é saber que se não compreende" (LD 116).

${ }^{41}$ LD 70. 
completa-se, de modo pouco legível,] a essência de cuja existência é mudar incessantemente." ${ }^{42}$

Poderíamos encontrar aqui um traço incipiente daquela transmutação nietzscheana de valores, a girar em volta de um eterno retorno, ou ler uma neurose paralisante cuja interpretação psicanalítica não poderíamos fazer. ${ }^{43}$ Encontramos, porém, um ponto importante para a nossa análise filosófica, a saber a menção do par conceptual essência e existência que pode fornecer uma chave a leitura do excerto. A essência é, efectivamente, aquilo que não passa, que se reveste de necessidade férrea e dura eternamente, ou se repete em exemplares, aparecendo na existência, fugazmente e de modos imperfeitos, alterados e sempre insuficientes. Pessoa define a eternidade justamente pela mediação do nada: "»passar para o nada«é »não passar «, é ser eterno" ${ }^{44}$ É a intensificação da negatividade no eu que permite negar a possibilidade sempre presente da perda de si integral do eu no seu outro, e recapturar esse outro sob a forma da superfície imagética, onírica ou sensacionista. Mas esta intensificação da negatividade mata qualquer possibilidade de sair novamente do círculo férreo e necessário do eu, cativo da sua identidade, plena de imagens e no gozo da lucidez absoluta da consciência de si mesmo, mas vazia, porque constituída pela negação. A patologia teórica causadora da dor é a adesão ao eu como essência imutável, ou antes, a incapacidade de sair do eu entendido como essência, incapacidade de aceitar o devir, não como perda imediata de si, mas como integração.

O sintoma mais notável desta relação paralisadora com a essência é a incapacidade de agir que Pessoa testemunha em diferentes textos. Assim, por exemplo,

"sempre que em mim há acção, reconheço que não fui eu." "O mundo é de quem não sente. A condição essencial para ser um homem prático é a ausência de sensibilidade." "A arte serve de fuga para a sensibilidade que a acção teve de esquecer." "A acção é uma doença do pensamento, um cancro da imaginação. Agir é exilar-se. Toda a acção é incompleta e imperfeita." "Parece-nos imoral agir." 45

42 Fernando Pessoa, Textos Filosóficos, Lisboa, 1968, I, 228.

${ }^{43}$ V. José Martinho, Pessoa e a Psicanálise (Coimbra, 2001), onde o nada psicanaliticamente "ilustra a incapacidade física de realização do amor no feminino" (67); sobre o nada, v. tb. ib. 77.

${ }^{44}$ Ib. 231.

${ }^{45}$ LD, 275, 286, 287, 302, 428. 
Apesar deste último aceno à questão da perfeição moral, a figura aqui esboçada é menos a da bela alma - que tratei numa sessão anterior destes seminários $^{46}$ - do que a da consciência infeliz hegeliana, cuja paralisia vem na sequência do cepticismo provocado pela derrocada do mundo antigo. Define Hegel a sua consciência infeliz de modo que reconheceríamos como perfeitamente pessoano, abstracção feita, naturalmente, do traço literário mais pesado do metafísico:

"a consciência infeliz é a consciência de si mesmo como a essência somente duplicada e contraditória". "A consciência da vida, do seu existir e agir é somente a dor acerca desse existir e agir, porque neles ela [a consciência infeliz] só tem a consciência do seu contrário como [consciência] da essência, e da sua própria nulidade." 47

A consciência infeliz de Pessoa renuncia então à acção, perante os condicionalismos inabarcáveis das situações do mundo, que a desaconselham vivamente, e assume uma posição constantemente a oscilar entre a infinita superioridade do homem educado, que tem o pudor de lançar as mãos aos pormenores menos elevados de quem quer ter causalidade sobre o mundo - chama-lhe Pessoa, metafisicamente, mesmo um "pudor de existir" 48 , a superioridade do homem lúcido que conhece a ingenuidade ou mesmo o dolo, a irresponsabilidade perante as consequências, requeridas por toda a tentativa de acção, por um lado e, por outro, a consciência da inferioridade e da ingenuidade ou desgraça ainda maior que é pretender estar acima do mundo. A infelicidade resulta deste conflito interior que apenas faz prolongar e acentuar a incapacidade para o comércio como mundo.

Poderiam adiantar-se outros sintomas deste conflito da consciência metafisicamente dividida pela visão excessivamente clara da negatividade da essência. Assim, por exemplo, o sintoma da própria concepção da prosa do Livro do Desassossego que, para o autor, é fundamentalmente imperfeita - ou tem, aliás, a sua razão e ser na própria imperfeição. Pergunta-se Bernardo Soares "por que escrevo eu este livro?" e responde,

"porque o reconheço imperfeito. Calado seria a a perfeição; escrito, imperfeiçoa-se; por isso o escrevo." 49

46 Ver Ferrer, "Hegel e as Patologias da Ideia", in Revista Filosófica de Coimbra, 27 (2005), 131-155.

${ }^{47}$ Hegel, Phänomenologie des Geistes, Hamburg, 1988, 144, 145.

${ }^{48}$ LD 154.

${ }^{49}$ LD 308. 
Este "imperfeiçoar-se" é, na verdade, a chave da estética do livro do desassossego, como resposta da consciência perante a sua negatividade interior, como reafirmação da possibilidade de existir sem violentar a própria consciência. "Imperfeiçoar-se" é desfazer a essência como existência. Ou antes, a essência já é em si mesma uma negação, expõe-se na imperfeição existêncial. Ou, sustentada no 'imperfeiçoar-se', a opção metodológica por uma hermenêutica contrária a qualquer definição, que decide, por isso "nunca ler um livro até ao fim". ${ }^{50}$

Vimos que a relação complexa e especular do eu, que permite definir negativamente a noção da essência, é produtora de imagens, sensações e aparências. Se, na vertente do sonho e da "navegação" no espaço da sensação, o resultado da noção de aparência, a que pertence essencialmente à essência, é a total desrealização do mundo, o qual se transmuta em material da pura estética e poética, já ao nível da elaboração artística, a mesma aparência se manifesta como o conhecido "fingimento" de Pessoa. Este fingimento não é, por conseguinte, uma questão de sinceridade, psicológica ou outra, ou de um qualquer saber do poeta, de si ou do mundo, mas é sinal da tomada e consciência do problema de que a essência só pode existir por meio da produção da aparência, do não essencial que se poderá então entender, nessa tomada de consciência, já não como ilusão, mas como manifestação e fenómeno. Por isso

"exprimir é sempre errar. Sê consciente: exprimir seja, para ti, mentir." 51

A mentira é o nome, dramática e vivencialmente acentuado, da condição da expressão poética, cuja verdade essencial seria antes o eterno silêncio. Mas a negação do silêncio que representa a verdade essencial interior é, também, a descoberta de que o caminho para o exterior, o "puro exterior" tematizado por José Gil a propósito da figura de Caeiro, passa pela sensação, pelas possibilidades da expressão poética e filosófica, isto é, pela ilusão inessencial, que se revela, invariavelmente, como essencial à essência, verdadeira porém muda. Caeiro apresenta-se, como pretende José Gil, como solução, mas o imediato assim atingido depende da negação da mediação realizada. Caeiro é o que de mais próximo se pode atingir do céu pessoano:

${ }^{50}$ LD 442. Ou a seguinte máxima: "Ter opiniões definidas e certas, instintos, paixões e carácter fixo e conhecido - tudo isto monta ao horror de tornar a nossa alma um facto, de a materializar e tornar exterior" (ib. 450). Mas isto é justamente a negação de qualquer obra.

${ }^{51}$ LD 321. 
"poder ser tu, sendo eu!

Ter a tua alegre inconsciência,

E a consciência disso! Ó céu!"52

Nada poderia ser mais claro. Trata-se, no centro da heteronomia, de poder ser Caeiro sem deixar de ser Pessoa, o que este realizou com toda a perfeição.

\section{Maturação e desenvolvimento da consciência}

Da perspectiva adquirida, poderá apontar-se para as possíveis soluções que dela irradiam, resoluções artísticas e de carne e osso, deste paradoxo, dolorosamente sentido por Pessoa como patologia existencial e vivencial. A interpretação tradicional da obra e da vida de Pessoa, cristalizada na grande biografia de João Gaspar Simões, vê no poeta um indivíduo preso numa situação infantil mal resolvida:

"o poeta da Mensagem não transcende a fase infantil por que passam, afinal, muitos génios literários." 53

A interpretação não é de modo nenhum descabida, dados os sintomas, alguns dos quais já apontámos, de recusa do mundo, a caracterizar aparentemente um receio infantil perante a "brutalidade e indiferença, que constitui o fundo visível das coisas," ou do mundo adulto, ${ }^{54}$ ou uma imatura ânsia juvenil pela inatingível perfeição.

$52 O C, \mathrm{I}, 111$.

53 João Gaspar Simões, Vida e Obra de Fernando Pessoa. História de uma Geração, Lisboa, 1950 [=JGS], I, 262.

${ }^{54}$ LD 153. Veja-se o diagnóstico de Martinho que, apesar de todas as vias de resolução da neurose encontradas na vida e obra de Pessoa, conclui, psicanaliticamente de modo negativo, porquanto "apesar de ter desejado conquistar o lugar do pai e do padrasto no amor materno, de ter querido ser um verdadeiro homem diante de uma mulher, Pessoa nunca o conseguiu" (Martinho, Pessoa e a Psicanálise, 50). Criticamente desastrado, enfermo de cegueira literária e por vezes tão só literal, a despeito da possivel pertinência das observações clínicas, é o diagnóstico psiquiátrico-literário de Mário Saraiva, Pessoa Ele Próprio e $O$ Caso Clínico de Fernando Pessoa. Na senda da análise médica do caso Pessoa, de uma lucidez incomparável com essa era já Daniel Serrão nos seus "Elementos para uma Patografia de Fernando Pessoa" (in Praça Nova, Dezembro de 1962, 9-10). V. tb. Idem, "Fernando Pessoa e a Mística (ou Mistério) do Mestre" in Nova Renascença, 1988, 148-154. 
O exercício poético e filosófico de Pessoa conduziu, de facto a consciência

"longe dos caminhos de mim próprio, cego da visão da vida que amo, cheguei por fim, também ao extremo vazio das coisas, à borda imponderável dos limites dos entes [...]." 55

Neste nada que bordeja o ente ${ }^{56}$ Pessoa encontrou que isso que constitui a prisão do eu na sua imutabilidade e incapacidade de desenvolvimento para uma maturação é o próprio negativo que se nega a si mesmo - iva $\tau \varepsilon \lambda \varepsilon \omega \varsigma$ av $\varepsilon 1 v \alpha \imath$.

Este estudo constitui, na verdade, a introdução para a fundamentação de diversas teses, que se poderia apresentar como chaves de maturidade e de maturação em Pessoa, que lhe permitiram viver, ao contrário, por exemplo, de Mário de Sá Carneiro. Contrariamente à visão que o coloca preso na infância, poderíamos localizar diversas vias de maturação e crescimento, como as seguintes.

1. Pessoa não negou imediatamente a vida, mas por mediações, como, de resto, é uma situação antropológica geral. Leia-se, por exemplo, a este propósito, o seguinte excerto:

"chega-nos [...] a ânsia da vida, de conhecer sem ser com o conhecimento, de meditar só com os sentidos ou pensar de um modo táctil ou sensível $[\ldots] " .57$

É isto negação da vida, como pretende o lugar comum sobre o autor? Pelo contrário, é a intensidade da ânsia que exige, "para que seja plenamente", a negação reiterada da vida. ${ }^{58}$

2. A crise de 1914, com o surgimento dos heterónimos e, especialmente Caeiro. ${ }^{59}$ Esta crise representou uma possibilidade de crescimento e evolução a partir provavelmente de um esteticismo provocatório próprio da juventude, em direcção a uma mais sólida maturação do fingimento, como superação de uma essência negativa.

${ }^{55}$ LD 147.

56 Veja, a este respeito, J. Enes, Noeticidade e Ontologia (Lisboa, 1999, 146-147).

${ }^{57}$ LD 119.

58 Insiste na positividade da vida em Pessoa, José Gil, Fernando Pessoa ou a Metafísica das Sensações (Lisboa, 1987, 247-249), contra "os críticos [que] fizeram dele o poeta do não-ser, do nada, do 'não-amor', da ausência" (ib. 247). Naturalmente, que a negação como tema central e mesmo uma teoria da mesma esteja presente em Pessoa não impede a positividade que dela resulta, como vimos.

59 Para o tema, muitíssimo explorado, v. 
3. A própria figura de Caeiro, que tão bem parece resolver o problema da consciência infeliz, em poesias como:

"Por isso quando num dia de calor

Me sinto triste de gozá-lo tanto,

E me deito ao comprido na erva,

E fecho os olhos quentes,

Sinto todo o meu corpo deitado na realidade,

Sei a verdade e sou feliz." 60

E resolve-o tão bem que - conforme se referiu - José Gil pergunta mesmo, como pode ter havido heterónimos depois de Caeiro. Mas, como vimos acima, talvez aqui o crítico seja ingénuo ao não observar que a solução, como supressão da mediação negativa, não é nunca definitiva.

4. A própria realização literária, como realização existencial da essência negativa do eu, realização ou, imperfeitamente dito, "plenitude"61 que tornou a Pessoa a dor tolerável. A propósito, escreve Soares:

"creio[-me] o primeiro a entregar a palavras o absurdo sinistro desta sensação [mais negativa do que o nada] sem remédio. E curo-a com o escrevê-la." 62

A positividade da maturação é encontrada na capacidade de transformar a realidade pela prática conseguida do rigor da expressão. Lemos, neste item:

"Dizer! Saber dizer! Saber existir pela voz escrita e a imagem intelectual! Tudo isto é quanto a vida vale [...]." ${ }^{\prime 63}$

5. Trata-se, em consequência da tese anterior, da capacidade de encontrar, no desenvolvimento da criação, a função divina de criar, pela expressão verdadeira, em sentido artístico e literário, a identidade própria. Acerca deste ponto leia-se o seguinte.

"Mas se quiser dizer que existo como entidade que a si mesma se dirige e forma, que exerce junto de si mesma a função divina de se criar, como hei-

${ }^{60} O C$, III, 38. V. José Gil, $D N, 43$.

61 Vila Maior, op.cit., 501, 519, 617. V. tb. Jacinto do Prado Coelho, Diversidade e Unidade em Fernando Pessoa, Lisboa, 1963, 206.

${ }^{62}$ LD 157.

${ }^{63}$ LD 141. 
de empregar o verbo "ser" senão convertendo-o subitamente em transitivo? E então, triunfalmente, antigramaticalmente supremo, direi "Sou-me"." "Cada homem que sabe dizer o que diz é, em seu modo, Rei de Roma. O título não é mau, e a alma é ser-se." 64

Ser-se é condição sina qua non até mesmo para a experiência eventualmente feliz e ultra-sensacionista da queda de todas as Romas subjectivas.

6. Biograficamente, mais do que uma vez foi já revisto o mito do poeta em vida fracassado. Pessoa recebeu o reconhecimento privado e público de um autor que foi dos mais publicados no meio literário português da sua época, que venceu prémios, cativou admiradores, foi reconhecido como mestre a partir principalmente de José Régio e da Presença, editada pela Imprensa da Universidade de Coimbra, e um criador que intimamente conhecia a sua própria valia, ${ }^{65}$ para além até mesmo de algum prestígio profissional, conforme enuncia, de modo insuspeito, Jorge de Sena, que retrata Pessoa "a cavalo no seu prestígio de correspondente comercial" em Lisboa. ${ }^{66}$

7. O amor por aspectos da vida enunciado na sua obra (por exemplo, pela cidade de Lisboa) e vivido na história de que são testemunhas as conhecidas cartas de amor - história que excede claramente os objectivos deste estudo.

Este enunciado de teses, ou tópicos, aponta para elaboração da questão da positividade na obra de Pessoa, ou mesmo de uma possível antropologia pessoana que permita livrar o poeta, tanto quanto for justo, da figura da consciência infeliz. Muito da riqueza extraordinária da sua criação poética e filosófica deriva deste saber das oposições irremediáveis de que sofre a consciência, saber de que

"só os Deuses, talvez, poderão sintetizar."67

${ }^{64}$ LD 114.

65 Acerca destes pontos v. JGS, 333-4, 340-1; ; José Martinho, op.cit., 83; Sena, FP, 230.

66 Sena, FP, 188.

${ }^{67}$ Fernando Pessoa, Textos Filosóficos, Lisboa, 1968, I, 4. 